\title{
Curb descent testing of suspension manual wheelchairs
}

\author{
Andrew M. Kwarciak, MS; ${ }^{1-3}$ Rory A. Cooper, PhD; ${ }^{1-4 *}$ Shirley G. Fitzgerald, PhD ${ }^{1-2}$ \\ ${ }^{1}$ Human Engineering Research Laboratories, Department of Veterans Affairs (VA) Center of Excellence in Wheel- \\ chairs and Associated Rehabilitation Engineering, VA Pittsburgh Healthcare System, Pittsburgh, PA; Departments of \\ ${ }^{2}$ Rehabilitation Sciences and Technology, School of Health and Rehabilitation Sciences, ${ }^{3}$ Bioengineering, School of \\ Engineering, and ${ }^{4}$ Physical Medicine and Rehabilitation, School of Medicine, University of Pittsburgh, Pittsburgh, PA
}

\begin{abstract}
Manual wheelchair users are subjected to wholebody vibrations (WBV) on a regular basis as they traverse obstacles and uneven surfaces. One way users could protect themselves from secondary injuries related to WBV is by using a suspension manual wheelchair. This study investigated the ability of suspension manual wheelchairs to reduce seat accelerations during curb descents of various heights $(5,10$, and $15 \mathrm{~cm}$ ). Sixteen manual wheelchairs (four suspension, four folding, four rigid, and four rigid titanium) were tested. Suspension wheelchairs transmitted significantly lower peak seat accelerations than folding wheelchairs during the $5 \mathrm{~cm}$ curb descents $(p=0.048)$ and significantly lower frequencyweighted peak seat accelerations during the 5 and $10 \mathrm{~cm}$ curb descents ( $p=0.03$ for both heights). However, when the suspension wheelchair Quickie XTR (Sunrise Medical; Carlsbad, California) was removed from the analysis, the suspension wheelchairs were not significantly different from the nonsuspension wheelchairs. When weight was considered, the suspension wheelchairs had significantly lower peak seat accelerations than the lighter rigid wheelchairs during $5 \mathrm{~cm}$ curb descents $(p=0.047)$. While suspension manual wheelchairs offer some reduction in WBV during curb descents, their limitations should be considered when a wheelchair is selected for everyday use.
\end{abstract}

Key words: acceleration, curb descent, folding frame, manual wheelchair, rehabilitation, rigid frame, suspension, vibration suppression, wheelchair use, whole-body vibrations.

\section{BACKGROUND}

Much research has been done on whole-body vibrations (WBV) and their potentially damaging effects on the human body, and though no definitive relationship exists, the development of low back pain and secondary injuries in persons exposed to WBV has been well documented [1-5]. Recent studies have attempted to categorize the possible mechanisms of injury related to WBV [6-11] and develop models that could optimize preventive measures [12-15]. Although none of these investigators addresses the effects of WBV on wheelchair users, their conclusions may be used to improve wheelchair design and research.

Wheelchair use presents one of the greatest risks of low back pain and injury because of prolonged sitting and regular exposure to WBV. Without proper lumbar support

Abbreviations: $\mathrm{ACC}=$ peak seat accelerations, ANOVA $=$ analysis of variance, $\mathrm{COM}=$ center of mass, FWACC $=$ frequency-weighted peak seat accelerations, ISO = International Standards Organization, MANOVA = multiple ANOVA, VA = Department of Veterans Affairs, WBV = whole-body vibrations.

*Address all correspondence to Rory A. Cooper, PhD; Human Engineering Research Laboratories, VA Center of Excellence in Wheelchairs and Associated Rehabilitation Engineering, VA Pittsburgh Healthcare System, 151R1-H, 7180 Highland Drive, Pittsburgh, PA 15206.

Email: rcooper@pitt.edu

DOI: 10.1682/JRRD.2006.11.0142 
and trunk stability, wheelchair users typically adopt a slouched posture that is characterized by posterior tilting of the pelvis and flattening of the lumbar spine. This kyphotic posture increases trunk moment and disk deformation and leads to increased intradiscal pressure and pain $[8,16]$. For those who rely on wheelchairs as their primary means of mobility, this posture may be assumed for up to 14 hours a day (according to a study by Hoover et al. [17]). During this time, wheelchair users are subjected to a variety of repeated low-level vibrations as well as infrequent high-magnitude shock vibrations [18]. VanSickle et al. reported that most of the energy from these vibrations is absorbed by the wheelchair user [18].

The potential danger and discomfort caused by extensive exposure to WBV have motivated the development of better-adapted wheelchairs. Manufacturers of manual wheelchairs have integrated suspension systems into their designs in an effort to reduce vibration transmission. Several different approaches have been introduced, each featuring a different type of suspension element and wheelchair configuration. And though these suspension manual wheelchairs have been on the market for years, few studies have evaluated their ability to suppress vibrations [19-21]. Instead, the designs have been considered beneficial for wheelchair users, in part because they feature suspension systems that have been successful in the bicycle and automobile industries. To our knowledge, no proof of concept or numerical model exists that demonstrates the advantage or method of incorporating a wheelchair-adapted system. As a result, the success of wheelchair suspension remains mostly unproven.

This study evaluated the vibration suppression properties of 4 commercially available suspension manual wheelchairs and 12 nonsuspension manual wheelchairs. Previous studies have been limited by the small sample sizes and/or by the data acquisition methods. The latter limitation concerns testing the primary function of suspension manual wheelchairs-shock vibration suppression. Two of the four suspension manual wheelchairs tested in this study, the Quickie ${ }^{\circledR}$ XTR (Sunrise Medical; Carlsbad, California) and the Boing! (Colours by Permobil; Anaheim, California), feature spring-based suspension systems that are designed to provide shock absorption [22]. The remaining two wheelchairs each have a pair of elastomers that dampen vibrations. While elastomers may seem suited for low-level vibration suppression, their application in suspension systems appears to be intended for higher-level vibrations. Suppression of low-level vibrations can be achieved with suspension caster forks [23] and specialized wheelchair seating systems $[21,24]$. Therefore, this study examined vibrationsuppression performance during high-load activities.

Some of the most common high-load activities performed by active wheelchair users are curb descents. Even when curb descents are avoided, vibration loads experienced during regular daily activities can approach magnitudes of $50 \mathrm{~m} / \mathrm{s}^{2}$ [18]. The potentially damaging effect of these loads on wheelchair users has led to the inclusion of curb descent testing in the American National Standards Institute/Rehabilitation Engineering and Assistive Technology Society of North America wheelchair fatigue testing standards as well as in numerous studies of manual and powered wheelchairs and their components [18-19,23-27]. Thus, curb descents were chosen as an adequate test for evaluating the vibrationsuppression performance of suspension manual wheelchairs. We hypothesized that the mean peak seat accelerations (ACC) and the mean frequency-weighted peak seat accelerations (FWACC) generated during curb descents would be significantly lower for suspension manual wheelchairs than for folding, rigid, and rigid titanium (Ti) wheelchairs.

\section{METHODS}

All curb descents were performed in a wheelchair testing laboratory at the Department of Veterans Affairs (VA) Pittsburgh Healthcare System, Pittsburgh, Pennsylvania. We tested 16 different manual wheelchairs: 4 suspension (Barracuda [Everest \& Jennings; St. Louis, Missouri], Boing!, A-6S [Invacare Corp; Elyria, Ohio], and Quickie XTR), 4 folding (Epic [Everest \& Jennings], Action Xtra [Invacare Corp], Champion 1000 [Kuschall of America; Camarillo, California], and Quickie 2 [Sunrise Medical]), 4 rigid (Eclipse [Colours by Permobil], A4 [Invacare Corp], Quickie GP [Sunrise Medical], and Top End Terminator [Invacare Corp]), and 4 rigid Ti (A4 Ti [Invacare Corp], Quickie Ti [Sunrise Medical], Cross Sport Ti [TiLite; Kennewick, Washington], and Top End Terminator Ti [Invacare Corp]). The weight of each wheelchair and the mean weight for each wheelchair type are given in Table 1. For consistency, the same test pilot (44-year-old male, $68 \mathrm{~kg}$, thoracic 7-8 spinal cord injury, 23 years of wheelchair experience) and seat cushion 
Table 1.

Wheelchair weights without rear wheels. Weights were compared with $1 \times 4$ analysis of variance: significance was set at $p<0.05$.

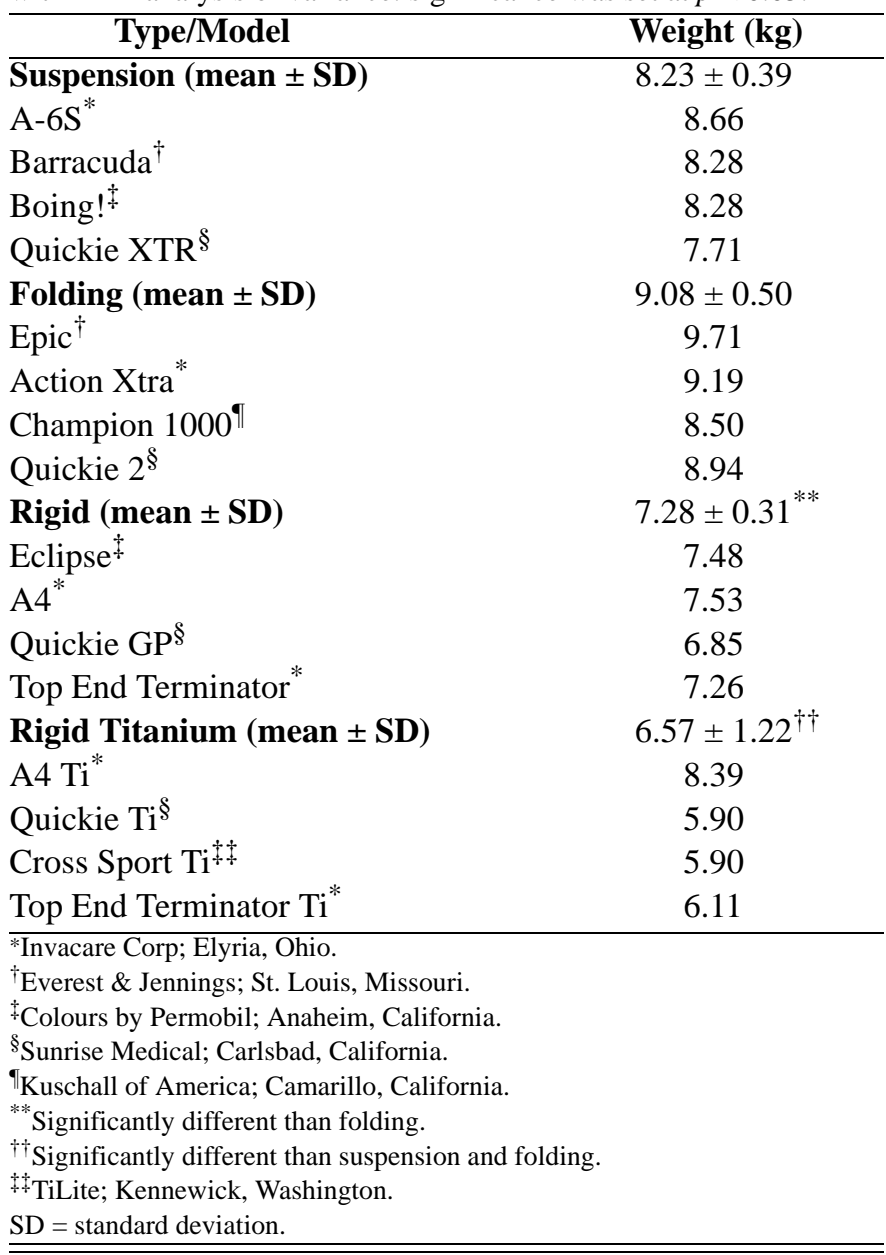

(Vicair ${ }^{\circledR}$ Academy [Vicair BV; Wormer, the Netherlands], $10.16 \mathrm{~cm}$ thick) were used throughout the testing.

Each wheelchair was adjusted to meet similar critical dimensions and fitted with similar rear wheels $(60.96 \mathrm{~cm}$ diameter, $4.55 \mathrm{~kg} / \mathrm{cm}^{2}$ ). The horizontal distance between the axle and the backrest was standardized to $4 \pm 1 \mathrm{~cm}$ for all wheelchairs to bring the center of mass (COM) of the wheelchair and the user to a similar position for all systems and to minimize differences from wheelchair setup (i.e., distance of the rear wheels from the COM). Seat angle also affects the location of the COM; however, due to the variability of the suspension systems upon compression, a consistent value could not be achieved. No adjustments were made to the wheelchair suspensions, since the purpose of adjustment is primarily for rider comfort. Further, the suspension wheelchairs were ordered to meet the size and weight specifications of the test pilot.
The test pilot was asked to descend three different height curbs $(5,10$, and $15 \mathrm{~cm}$ ) using each of the 16 wheelchairs in a randomized order (Figure 1). With each wheelchair, the test pilot was given time to become acclimated in the chair and comfortable performing a curb descent. The curbs consisted of a $5 \mathrm{~cm}$-thick reinforced wooden top and pairs of $5 \mathrm{~cm}$-thick supports when needed for additional height. Three sets of trials were performed for each wheelchair. Each set consisted of a randomized order of three different height curb descents (a total of nine descents for each wheelchair) onto a pair of calibrated force plates. The descent method specified for this testing was based on the technique used by the test pilot. For each descent, the test pilot maintained rolling contact with the curb for as long as possible by performing a wheelie. The test pilot first balanced the wheelchair on the rear wheels and then descended the curb such that the rear wheels struck the landing area first, precluding any confounding data that might otherwise appear if caster impact preceded rear wheel impact. This method constrained the definition of a curb descent, although it provided a stable, repeatable method for data collection. For comfort and safety, no constraints were placed on hand contact with the pushrims. The test pilot was free to maintain hand contact with the pushrims throughout the descent to maintain balance, particularly upon impact. In each wheelchair, the test pilot sat with his back and pelvis against the backrest and both feet flat on the footrest.

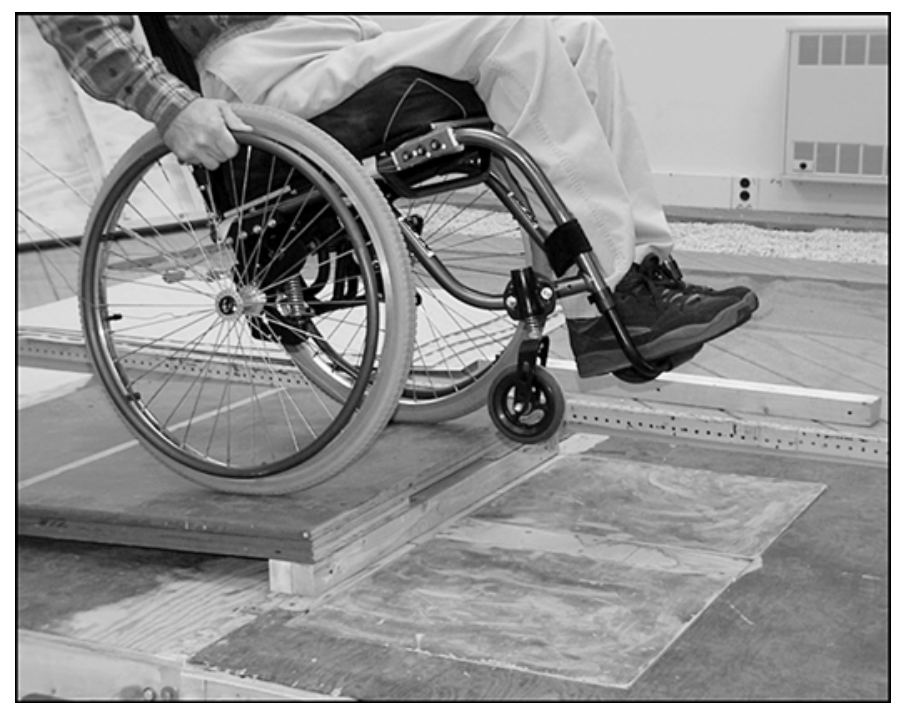

Figure 1.

Example of $10 \mathrm{~cm}$ curb descent. 


\section{Data Collection}

We collected seat accelerations with an instrumented seat plate that consisted of a $0.95 \mathrm{~cm}$-thick piece of aluminum fitted with a triaxial accelerometer (Crossbow Technology, Inc; San Jose, California). During testing, the seat plate was placed on the seat pan of each wheelchair underneath the seat cushion. Data were collected from the accelerometer at $200 \mathrm{~Hz}$, which provided sufficient sampling of the frequencies of interest for human vibration exposure $(0-50 \mathrm{~Hz})$. During each trial, someone followed the wheelchair in order to support the data logger that transferred acceleration data to the computer and to prevent the wires from interfering with testing.

In addition to accelerations, we measured wheelchair orientation using a calibrated Optotrak system (Northern Digital, Inc; Ontario, Canada). For each trial, we determined the orientation of the wheelchair by tracking the location of six active Optotrak markers: three placed on the right-seat portion of the frame, one on the axle, and two on the platform surrounding the landing area. We used one bank of three Optotrak cameras positioned to the right of the testing area to record marker positions at $300 \mathrm{~Hz}$.

\section{Data Reduction and Analysis}

Analysis of acceleration data was limited to vibrations in the vertical direction, normal to the seat of the wheelchair. These vibrations present the greatest risk to the comfort and spinal integrity of seated persons. Conse- quently, vertical vibrations within the frequency range that humans are most sensitive to $(4-12 \mathrm{~Hz})$ receive the highest frequency weighting according to International Standards Organization (ISO) 2631-1 [28]. We used several MATLAB ${ }^{\circledR}$ routines (The MathWorks, Inc; Natick, Massachusetts) to calculate the ACC and FWACC experienced during each curb descent. Application of ISO 2631-1 frequency weighting was consistent with previous analyses of seat acceleration data [24,29].

We used Optotrak marker data to calculate the wheelchair frame angle at impact with the lower surface and the two frame markers positioned farthest from the backrest to construct a line representing the seat (the third marker was disregarded because of instances of marker dropout). We used the same procedure to define the landing surface with the two platform markers; both lines represented the projection of the Optotrak markers in the global sagittal plane. We calculated frame angle using the dot product of the "seat line" and the "ground line" and their respective magnitudes. Impact was defined as the point where the axle height reached its minimum value. Using this point, we determined the corresponding frame angle and suspension angle at impact.

The suspension angle refers to the angle at which the axle approaches the seat during loading (Figure 2). For three of the four suspension wheelchairs, this angle was determined by measuring the angle of the suspension element(s) with respect to the ground while the wheelchair

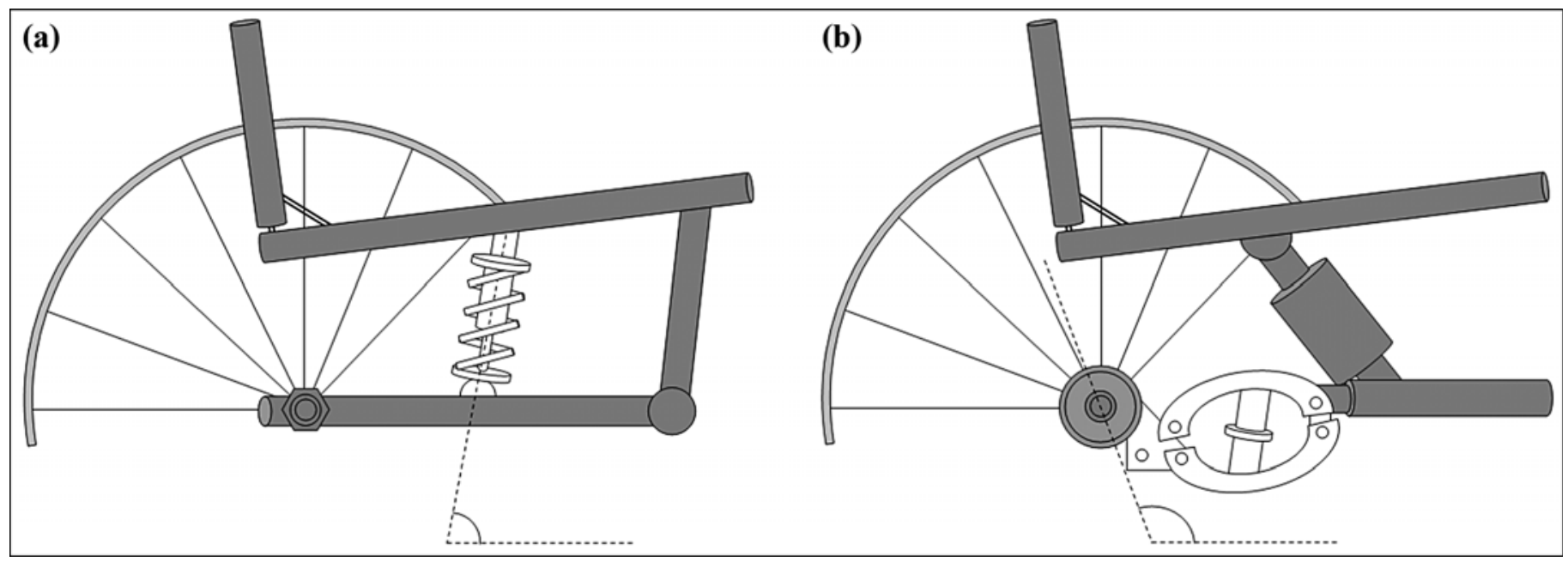

Figure 2.

Suspension angle for (a) Quickie XTR (Sunrise Medical; Carlsbad, California) and (b) A-6S (Invacare Corp; Elyria, Ohio). Dotted line represents path along which axle approaches seat. For ease of measurement, we assumed path was linear instead of arced. 
was positioned with all four wheels on the ground. For the A-6S, which features a ratcheting suspension mechanism [22], we found the suspension angle by measuring the movement of a point on the seat as the wheelchair was loaded. By summing the suspension angle with the angle of the frame at impact, we determined the angle of the suspension at impact. The suspension angle at impact was used to explain the acceleration data and to evaluate the effectiveness of the suspension systems.

\section{Statistical Analysis}

We used analysis of variance (ANOVA) to compare the results and to test the hypothesis that suspension manual wheelchairs transmit lower levels of vibration than nonsuspension folding, rigid, and rigid Ti manual wheelchairs. We calculated separate models for each set of dependent variables (ACC and FWACC). For each model, a multiple ANOVA (MANOVA) was performed to test the overall effect of curb height and the combined effect of curb height and wheelchair type. Then, we performed a
$1 \times 4$ ANOVA on the ACC and FWACC measured at each curb height. We used post hoc analyses with a simulated adjustment for multiple comparisons to identify significant differences between individual wheelchair types. All analyses were subsequently performed again with wheelchair weight included as a covariate. Wheelchair weight was not a controllable factor; however, accounting for how weight affected the measurements was important. All analyses were performed in SAS (SAS Institute, Inc; Cary, North Carolina) with significance set to $p<0.05$.

\section{RESULTS}

The ACC and FWACC calculated for each wheelchair for each curb height are presented in Table 2. For clarification, all assessments of acceleration data were based on magnitude and not sign. Reliable interclass correlation coefficients could not be obtained because of the

Table 2.

Peak seat accelerations and peak frequency-weighted seat accelerations. Data presented as mean \pm standard deviation.

\begin{tabular}{|c|c|c|c|c|c|c|}
\hline \multirow{2}{*}{ Type/Model } & \multicolumn{3}{|c|}{ Peak Seat Acceleration (m/s²) } & \multicolumn{3}{|c|}{ Peak Frequency-Weighted Seat Acceleration $\left(\mathrm{m} / \mathrm{s}^{2}\right)$} \\
\hline & $5 \mathrm{~cm}$ & $10 \mathrm{~cm}$ & $15 \mathrm{~cm}$ & $5 \mathrm{~cm}$ & $10 \mathrm{~cm}$ & $15 \mathrm{~cm}$ \\
\hline \multicolumn{7}{|l|}{ Suspension } \\
\hline A- $6 S^{*}$ & $-19.50 \pm 2.42$ & $-41.26 \pm 8.16$ & $-68.45 \pm 16.77$ & $-8.45 \pm 2.14$ & $-16.95 \pm 1.69$ & $-23.77 \pm 3.95$ \\
\hline Barracuda $^{\dagger}$ & $-27.50 \pm 1.92$ & $-33.26 \pm 7.62$ & $-61.41 \pm 15.98$ & $-12.16 \pm 0.88$ & $-17.25 \pm 4.06$ & $-28.94 \pm 7.97$ \\
\hline Boing $!^{\ddagger}$ & $-19.50 \pm 0.55$ & $-31.66 \pm 5.29$ & $-51.18 \pm 11.73$ & $-8.87 \pm 0.58$ & $-16.47 \pm 2.21$ & $-21.28 \pm 3.13$ \\
\hline Quickie XTR ${ }^{\S}$ & $-16.62 \pm 0.55$ & $-27.82 \pm 4.54$ & $-32.62 \pm 4.54$ & $-5.03 \pm 1.18$ & $-10.61 \pm 1.57$ & $-14.75 \pm 1.16$ \\
\hline \multicolumn{7}{|l|}{ Folding } \\
\hline Epic $^{\dagger}$ & $-28.46 \pm 5.84$ & $-51.82 \pm 12.15$ & $-56.61 \pm 7.20$ & $-13.08 \pm 4.61$ & $-26.65 \pm 5.29$ & $-31.46 \pm 6.22$ \\
\hline Action Xtra ${ }^{*}$ & $-31.66 \pm 3.63$ & $-47.98 \pm 9.47$ & $-54.38 \pm 11.68$ & $-15.36 \pm 1.43$ & $-26.53 \pm 4.95$ & $-29.26 \pm 3.67$ \\
\hline Champion 1000 & $-35.18 \pm 6.92$ & $-46.38 \pm 5.46$ & $-69.41 \pm 6.94$ & $-17.79 \pm 2.58$ & $-23.29 \pm 3.34$ & $-35.53 \pm 3.57$ \\
\hline Quickie $2^{\S}$ & $-30.70 \pm 9.07$ & $-39.98 \pm 8.20$ & $-45.42 \pm 4.33$ & $-14.17 \pm 3.84$ & $-20.06 \pm 4.25$ & $-24.67 \pm 5.46$ \\
\hline \multicolumn{7}{|l|}{ Rigid } \\
\hline Eclipse $^{\ddagger}$ & $-21.10 \pm 4.43$ & $-36.46 \pm 11.04$ & $-58.21 \pm 12.48$ & $-8.35 \pm 2.53$ & $-16.99 \pm 3.43$ & $-23.85 \pm 8.28$ \\
\hline $\mathrm{A} 4^{*}$ & $-33.58 \pm 12.23$ & $-46.70 \pm 11.52$ & $-59.49 \pm 13.62$ & $-14.84 \pm 3.91$ & $-20.15 \pm 4.89$ & $-33.46 \pm 3.69$ \\
\hline Quickie GP & $-31.02 \pm 5.79$ & $-47.02 \pm 2.00$ & $-61.73 \pm 18.82$ & $-12.89 \pm 4.26$ & $-23.08 \pm 4.82$ & $-29.74 \pm 7.33$ \\
\hline Top End Terminator* & $-22.70 \pm 9.60$ & $-34.54 \pm 4.43$ & $51.82 \pm 12.15$ & $-8.94 \pm 6.26$ & $-14.51 \pm 2.85$ & $-23.68 \pm 8.32$ \\
\hline \multicolumn{7}{|l|}{ Rigid Titanium } \\
\hline A4 $\mathrm{Ti}^{*}$ & $-30.06 \pm 4.00$ & $-49.90 \pm 9.66$ & $-62.69 \pm 14.53$ & $-14.53 \pm 3.11$ & $-22.87 \pm 4.15$ & $-30.89 \pm 6.38$ \\
\hline Quickie $\mathrm{Ti}^{\S}$ & $-21.74 \pm 3.84$ & $-35.18 \pm 6.29$ & $-52.46 \pm 6.65$ & $-9.68 \pm 3.19$ & $-16.81 \pm 2.04$ & $-29.95 \pm 4.09$ \\
\hline Cross Sport $\mathrm{Ti}^{* *}$ & $-31.34 \pm 2.93$ & $-41.90 \pm 8.71$ & $-52.14 \pm 26.13$ & $-14.72 \pm 1.21$ & $-22.43 \pm 2.78$ & $-20.01 \pm 7.40$ \\
\hline Top End Terminator $\mathrm{Ti}^{*}$ & $-24.94 \pm 3.46$ & $-32.94 \pm 5.34$ & $-74.53 \pm 10.26$ & $-11.99 \pm 0.77$ & $-13.61 \pm 5.73$ & $-33.98 \pm 2.20$ \\
\hline \multicolumn{7}{|c|}{ 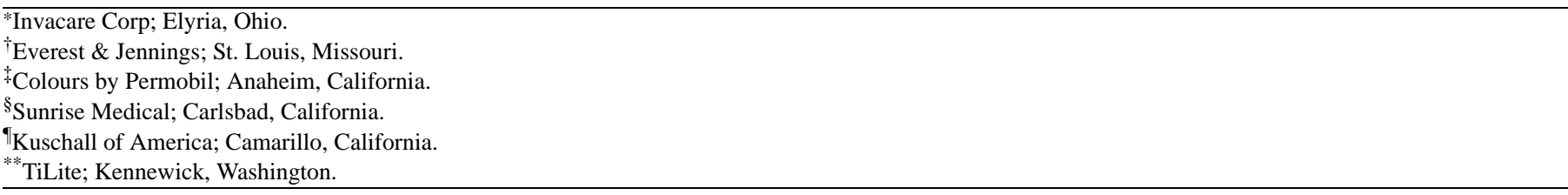 } \\
\hline
\end{tabular}


small number of individual wheelchair trials for each curb height and because of inconsistencies within each wheelchair type. MANOVA showed that curb height significantly affected acceleration (Wilks $\Delta, p<0.001$ ); however, no significant differences were found between the wheelchair types across curb heights (Wilks $\Delta, p=$ 0.86 for ACC and $p=0.82$ for FWACC). The lack of significance between types was also attributed to the relatively small and variable sample size. Despite these results, ANOVA revealed significant differences between the wheelchair types in terms of ACC during the $5 \mathrm{~cm}$ curb descents $(p=0.048)$ and FWACC during the 5 and $10 \mathrm{~cm}$ curb descents ( $p=0.03$ and 0.04 , respectively). Post hoc analyses showed that suspension wheelchairs transmitted significantly lower ACC $(p=0.03)$ and FWACC ( $p=0.02)$ than folding wheelchairs during $5 \mathrm{~cm}$ curb descents. For the $10 \mathrm{~cm}$ curb descent, suspension wheelchairs produced significantly lower FWACC ( $p=$ 0.03) than folding wheelchairs.

As a group, suspension wheelchairs had the lowest ACC for each curb descent height; however, individually they were not the four best wheelchairs for vibration suppression. For each curb descent height, at least one nonsuspension wheelchair, most frequently the rigid Eclipse or one of the Top End Terminators (rigid or rigid Ti), transmitted lower accelerations than one or more of the suspension wheelchairs. In addition, vibration-suppression performance decreased as the height of the curb increased (Figure 3).

For $15 \mathrm{~cm}$ curb descents, the differences in ACC between the suspension wheelchairs and the folding, rigid, and rigid Ti wheelchairs were $3.04 \mathrm{~m} / \mathrm{s}^{2}, 4.40 \mathrm{~m} / \mathrm{s}^{2}$, and $7.04 \mathrm{~m} / \mathrm{s}^{2}$, respectively. With the exception of the rigid Ti wheelchairs, these were the smallest differences between the wheelchair types for any of the three curb heights. In other words, the suspension wheelchairs performed most similarly to the folding, rigid, or rigid Ti wheelchairs during $15 \mathrm{~cm}$ descents. On the other hand, the differences in FWACC between the suspension wheelchairs and the nonsuspension wheelchairs increased between the 5 and $15 \mathrm{~cm}$ curb descents, which is a critical point in terms of wheelchair vibration-suppression performance. Considering that the ISO 2631-1 frequency-weighting system emphasizes perturbation frequencies to which the human body is most sensitive, analysis of FWACC provides a more specific indication of the injury risk associated with each wheelchair for each curb descent height.
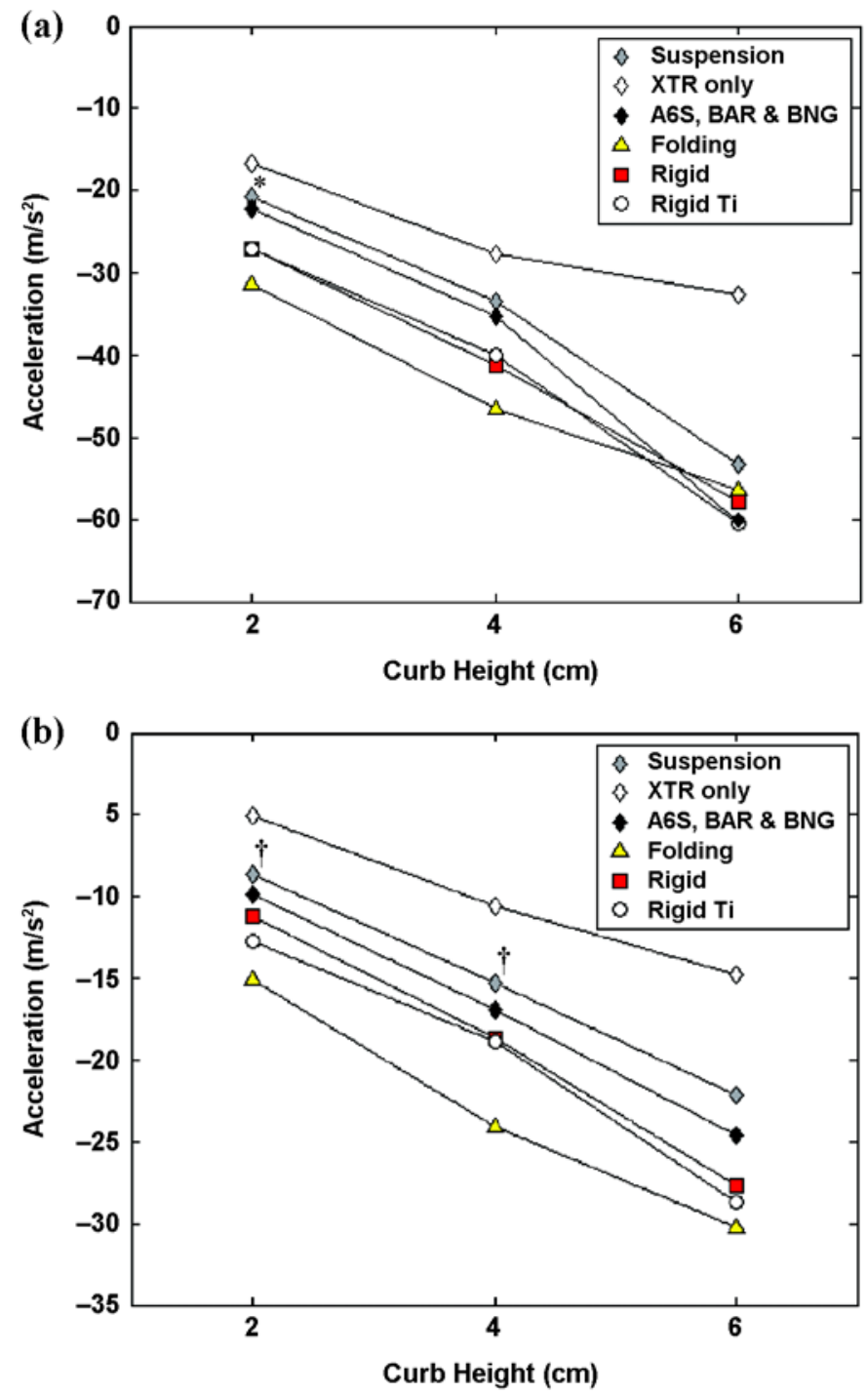

Figure 3.

Mean (a) peak seat accelerations (ACC) and (b) frequency-weighted peak seat accelerations (FWACC) for each wheelchair type for each curb height. * Significantly lower ACC than folding $(p=0.03)$. ${ }^{\dagger}$ Significantly lower FWACC than folding $(p<0.05)$. XTR $=$ Quickie XTR (Sunrise Medical; Carlsbad, California), A6S = A-6S (Invacare Corp; Elyria, Ohio), BAR = Barracuda (Everest \& Jennings; St. Louis, Missouri), BNG = Boing! (Colours by Permobil; Anaheim, California).

We must also note that the significantly lower ACC and FWACC recorded from the suspension wheelchairs were attributed to the superior vibration-suppression performance of the Quickie XTR. The Quickie XTR transmitted the smallest ACC and FWACC for each curb descent height. When the Quickie XTR was removed from the statistical analysis, the suspension wheelchairs 
were not found to be significantly different than any of the other types. While the remaining suspension wheelchairs had lower accelerations for the 5 and $10 \mathrm{~cm}$ curb descents, only when the Quickie XTR was included were results significant. Figure 4 shows FWACC versus time for a single Quickie XTR trial and a single Kuschall Champion 1000 (folding frame) trial. These wheelchairs transmitted the lowest and highest FWACC, respectively, for the $15 \mathrm{~cm}$ curb descents.

When the ANOVA was calculated with weight included as a covariate, changes in significance occurred. In terms of ACC, differences between wheelchair types were more significant for the $5 \mathrm{~cm}$ curb descents $(p=$ $0.03)$. Post hoc analysis revealed that suspension wheelchairs produced significantly lower accelerations ( $p=$ 0.047 ) than rigid wheelchairs. Nearly significant differences were found between suspension and rigid Ti wheelchairs $(p=0.05)$. In terms of FWACC, significant and nearly significant differences were found between wheelchair types for the 5 and $10 \mathrm{~cm}$ curb descents ( $p=0.045$ and 0.05 , respectively); however, post hoc analysis revealed no significance differences between individual wheelchairs.

\section{DISCUSSION}

Each of the four suspension manual wheelchairs tested in this study has a unique approach to vibration reduction; however, all the models seem focused on reducing shock vibrations acting normal to the seat of the wheelchair. Based on the expected ability and experience level of a suspension manual wheelchair user, curb descents were selected as a means by which comparisons of shock vibration transmissibility could be made. Curb descents demand stability and control, often requiring the user to perform and maintain a wheelie in order to avoid falling forward out of the wheelchair on impact with the lower surface. During this process, the benefit of the suspension system may be compromised because of the orientation of the wheelchair [19]. For this reason, we used Optotrak markers to identify the position of the wheelchair with respect to the test surface, which provided an approximation of the wheelchair frame angle that we used to interpret the results.

Table 3 shows the mean seat angle at impact for each wheelchair at each curb height. Table 4 shows the mean suspension angle at impact for each suspension wheelchair as well as the differences between the resting suspension

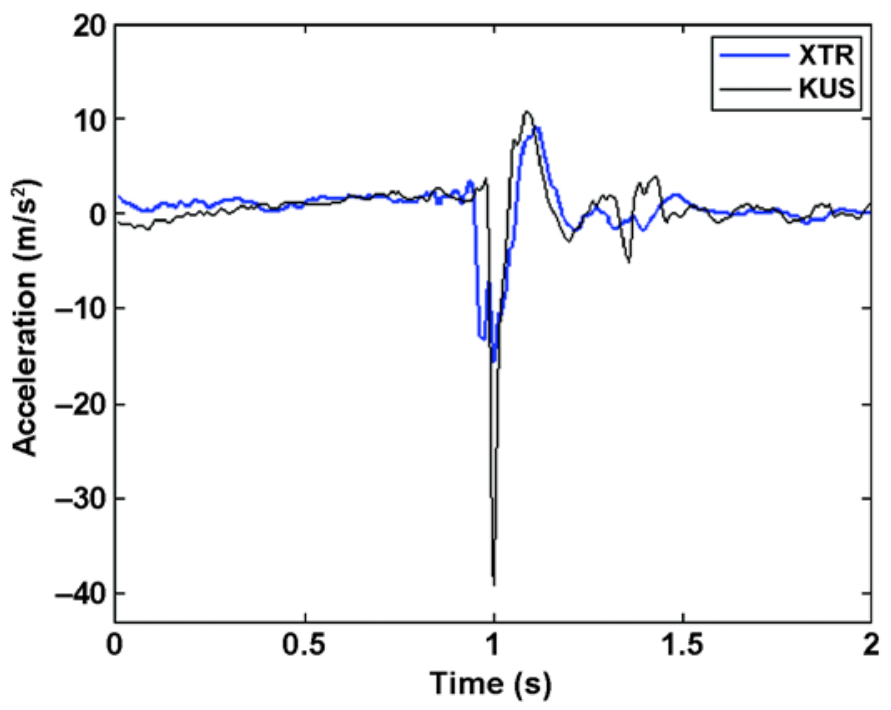

Figure 4.

Example of frequency-weighted peak seat accelerations collected during $15 \mathrm{~cm}$ curb descent with Quickie XTR (XTR) (Sunrise Medical; Carlsbad, California) and Champion 1000 (KUS) (Kuschall of America; Camarillo, California). Data from each trial was trimmed to align impact spikes and focus on time surrounding impact.

Table 3.

Mean frame impact angles for three different curb heights.

\begin{tabular}{|c|c|c|c|}
\hline \multirow{2}{*}{ Type/Model } & \multicolumn{3}{|c|}{ Mean Frame Impact Angle } \\
\hline & $5 \mathrm{~cm}$ & $10 \mathrm{~cm}$ & $15 \mathrm{~cm}$ \\
\hline Suspension (mean \pm SD) & $26.85 \pm 2.88$ & $31.36 \pm 3.05$ & $31.95 \pm 3.49$ \\
\hline $\mathrm{A}-6 \mathrm{~S}^{*}$ & 27.64 & 31.93 & 34.39 \\
\hline Barracuda $^{\dagger}$ & 28.51 & 35.55 & 32.87 \\
\hline Boing! $!^{\ddagger}$ & 24.76 & 30.23 & 33.12 \\
\hline Quickie XTR ${ }^{\S}$ & 26.50 & 27.92 & 27.83 \\
\hline Folding (mean \pm SD) & $22.30 \pm 1.34$ & $25.25 \pm 3.14$ & $26.96 \pm 1.76$ \\
\hline Epic $^{\dagger}$ & 22.82 & 23.07 & 26.87 \\
\hline Action Xtra ${ }^{*}$ & 20.97 & 24.29 & 26.06 \\
\hline Champion $1000^{q}$ & 22.18 & 25.34 & 26.92 \\
\hline Quickie $2^{\S}$ & 23.24 & 28.29 & 27.97 \\
\hline Rigid (mean \pm SD) & $21.59 \pm 6.56$ & $25.42 \pm 6.00$ & $25.72 \pm 4.69$ \\
\hline Eclipse $^{\ddagger}$ & 29.56 & 30.99 & 28.23 \\
\hline $\mathrm{A} 4^{*}$ & 14.29 & 18.64 & 19.77 \\
\hline Quickie GP ${ }^{\S}$ & 18.14 & 21.53 & 23.95 \\
\hline Top End Terminator ${ }^{*}$ & 24.38 & 30.52 & 30.90 \\
\hline Rigid Titanium (mean \pm SD) & $22.42 \pm 2.44$ & $26.80 \pm 5.73$ & $26.20 \pm 4.44$ \\
\hline $\mathrm{A} 4 \mathrm{Ti}^{*}$ & 20.08 & 21.41 & 21.26 \\
\hline Quickie $\mathrm{Ti}^{\S}$ & 22.26 & 22.78 & 23.34 \\
\hline Cross Sport $\mathrm{Ti}^{* *}$ & 23.24 & 30.55 & 31.29 \\
\hline Top End Terminator Ti ${ }^{*}$ & 24.10 & 32.43 & 28.93 \\
\hline $\begin{array}{l}\text { *Invacare Corp; Elyria, Ohio. } \\
{ }^{*} \text { Everest \& Jennings; St. Louis, } \\
{ }^{\ddagger} \text { Colours by Permobil; Anahein } \\
{ }^{\S} \text { Sunrise Medical; Carlsbad, Ca } \\
{ }^{9} \text { Kuschall of America; Camaril } \\
{ }^{* *} \text { TiLite; Kennewick, Washingt } \\
\text { SD = standard deviation. }\end{array}$ & $\begin{array}{l}\text {, Missouri. } \\
\text { m, California. } \\
\text { alifornia. } \\
\text { llo, California. } \\
\text { ton. }\end{array}$ & & \\
\hline
\end{tabular}


JRRD, Volume 45, Number 1, 2008

Table 4.

Nominal suspension angles and mean angles of suspension at impact.

\begin{tabular}{|c|c|c|c|c|c|c|c|}
\hline \multirow[t]{2}{*}{ Model } & \multirow[t]{2}{*}{$\begin{array}{l}\text { Suspension } \\
\text { Angle }\end{array}$} & \multicolumn{3}{|c|}{$\begin{array}{l}\text { Mean Suspension Angle at Impact } \\
\text { (mean } \pm \text { standard deviation) }\end{array}$} & \multicolumn{3}{|c|}{$\begin{array}{l}\text { Difference Between Suspension Angle at } \\
\text { Impact and Resting Suspension Angle } \\
\text { (mean } \pm \text { standard deviation) }\end{array}$} \\
\hline & & $5 \mathrm{~cm}$ & $10 \mathrm{~cm}$ & $15 \mathrm{~cm}$ & $5 \mathrm{~cm}$ & $10 \mathrm{~cm}$ & $15 \mathrm{~cm}$ \\
\hline $\mathrm{A}-6 \mathrm{~S}^{\dagger}$ & 85.2 & $112.8 \pm 0.3$ & $117.1 \pm 2.1$ & $119.6 \pm 4.0$ & $27.6 \pm 0.3$ & $31.9 \pm 2.1$ & $34.4 \pm 4.0$ \\
\hline Boing! $!^{\ddagger}$ & 101.0 & $125.8 \pm 2.7$ & $131.2 \pm 1.2$ & $134.1 \pm 3.7$ & $24.8 \pm 2.7$ & $30.2 \pm 1.2$ & $33.1 \pm 3.7$ \\
\hline
\end{tabular}

angle and the suspension angle at impact for all three curb heights. Assuming the vibration-reducing capability of each suspension system is maximized for accelerations traveling along the suspension angle, then each of the mean suspension angles listed in Table $\mathbf{4}$ indicates the ideal impact angle for the system. Because the primary direction of force and vibration transmission was normal to the lower surface, the ideal impact angle is $90^{\circ}$. The relative proximity of the Quickie XTR suspension to $90^{\circ}$ at impact may explain why it was the best overall wheelchair in terms of ACC and FWACC transmission for all curb descent heights. The Barracuda and the Boing!, the wheelchairs with the two highest suspension angles at impact, produced the greatest average overall accelerations. For these wheelchairs, the high suspension angles correlated to poor vibration-suppression performance that was comparable to wheelchairs without suspension systems. However, the angle for the A-6S, which was second lowest among suspension wheelchairs, did not translate into good vibration suppression. For $15 \mathrm{~cm}$ curb descents, the A-6S produced the third highest ACC of all wheelchairs tested. This result suggests that the vibration-suppression performance of the suspension wheelchairs is also dependent on the type of suspension elements used.

The A-6S and the Barracuda both feature elastomerbased systems that include multiple elastomers to provide bilateral suspension. The Boing! features independent suspension: two metal springs regulate compression of its multilinkage frame. Finally, the Quickie XTR has a single RockShox ${ }^{\circledR}$ (SRAM Corp; Chicago, Illinois) mountain bike shock that couples the axle and lower frame to the seat. This configuration is the most sophisticated suspension element used in any of the four suspension wheelchairs. As the data show, each system has advantages and limitations.
The data collected from $5 \mathrm{~cm}$ curb descents tended to corroborate the original notion that wheelchair vibrationsuppression performance was determined by suspension angle at impact. The two wheelchairs with the lowest impact angles, the Quickie XTR and the A-6S, had the lowest ACC and FWACC, followed closely by the Boing! and finally the Barracuda. The Barracuda had the worst vibration suppression of all suspension wheelchairs. We suspect that the extreme posterior position of the suspension elements of this wheelchair does not allow for much energy absorption (Figure 5). The Barracuda was also the only wheelchair with a solid seat pan, which most likely resulted in higher vibration transmission. During the $5 \mathrm{~cm}$ curb descents, the Barracuda transmitted more harmful

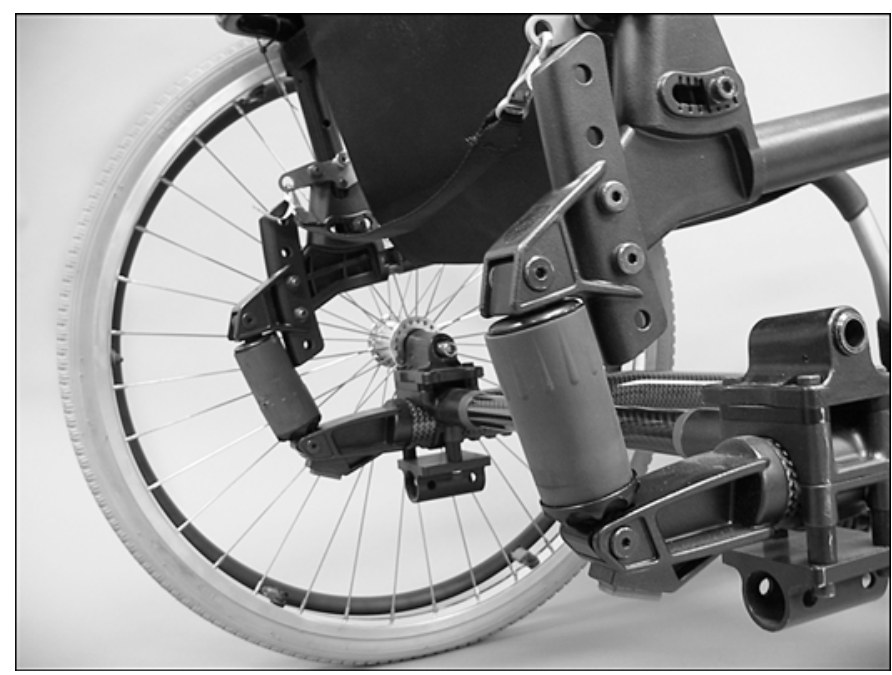

Figure 5.

Elastomer suspension system of Barracuda suspension manual wheelchair (Everest \& Jennings; St. Louis, Missouri). 
vibrations (within the $4-12 \mathrm{~Hz}$ range) than four of the rigid wheelchairs (two aluminum, two Ti).

On $10 \mathrm{~cm}$ curb descents, the limitations of the suspension manual wheelchairs became apparent. The A-6S was the worst suspension wheelchair in terms of ACC for this height. Interestingly, it remained one of the best wheelchairs in terms of FWACC, exemplifying the ability of the elastomers to reduce and/or properly shift low-frequency vibration. The Boing! and the Barracuda reduced vibration transmission but failed to outperform the Top End Terminator Ti, which had lower ACC than the Barracuda and lower FWACC than both the Barracuda and the Boing!. Lower FWACC were also presented by the nonsuspension Top End Terminator. Apparently, the increase in frame angle required for safe descent of the larger curb height limited the capability of the suspension systems. This limitation seemed to hold true for all suspension wheelchairs except the Quickie XTR, which presented the lowest mean ACC of all wheelchairs.

Considering these results, we should note that FWACC became more important in the assessment of wheelchair suspension as curb height increased. The impacts associated with the two higher curb descents excited the wheelchair with more frequency modes, which are presumably beyond the natural frequency range of the human body. So, while ACC may increase dramatically between 5 and $15 \mathrm{~cm}$ curb descents, FWACC may not increase proportionally. In other words, manual wheelchair users may not be as sensitive or vulnerable to the additional, higher frequency modes generated from 10 and $15 \mathrm{~cm}$ curb descents. Therefore, we need to emphasize FWACC, which isolate those vibrations that pose the greatest risks of pain and secondary injury.

Results of the $15 \mathrm{~cm}$ curb descents helped to further establish and explain the trends in the capability of wheelchair suspension. In terms of FWACC, the suspension wheelchairs maintained the smallest average magnitude. Across the three curb heights, they showed a nearlinear increase in FWACC, unlike the rigid and rigid Ti wheelchairs, which showed a markedly steeper increase between 10 and $15 \mathrm{~cm}$ descents (Figure 3). This finding demonstrates the ability of the suspension systems to lessen the effect of larger rear wheel impacts. However, in terms of ACC, the suspension wheelchairs performed more closely than ever to the nonsuspension wheelchairs. The high values measured for the A-6S and the Barracuda greatly increased the ACC average for the group. As expected, the $15 \mathrm{~cm}$ curb height yielded the highest overall mean suspension angle at impact $\left(\sim 124.5^{\circ}\right)$. At this angle, the elastomer-based suspensions were relatively ineffective at reducing accelerations, although they continued to provide reduction in FWACC. Further analysis is required to determine how the location and orientation of the elastomers affect their ability to reduce accelerations associated with curb descents. Though elastomer suspension systems do not appear useful for suppressing high-load shock vibrations, they should be considered for their ability to suppress low-frequency oscillations. Perhaps elastomers could be used to couple sections of the wheelchairs where vibrations are greatest.

Unlike the A-6S and the Barracuda, the Quickie XTR and Boing! were relatively successful in reducing the accelerations resulting from the $15 \mathrm{~cm}$ curb descents. The success of the Quickie XTR may be attributed to a welldesigned suspension element, which provided the most travel and dampening of any suspension system tested as well as a low suspension angle. The Quickie XTR had the smallest suspension angle at impact on every curb descent as well as the smallest change in angle from 5 to $15 \mathrm{~cm}$ curb descents $\left(1.13^{\circ}\right)$. These small angle changes were possible because of a more posterior COM (associated with the cantilever frame). Overall, the influence of the Quickie XTR was evident when the wheelchair was removed from the analysis. Without the Quickie XTR, the accelerations obtained from the suspension wheelchairs were statistically similar to those from the other wheelchair types. Although the change in significance could have resulted from the loss of one degree of freedom in the statistical model, it is most likely because of the relatively small amount of acceleration the Quickie XTR transmitted to the seat. On the other hand, we suspect the success of the Boing! is from the undamped springs used in the suspension. Despite their high angle at impact, the springs may still have had considerable compression and energy absorption capabilities. This absorption is particularly apparent in the higher curb descents, where the Boing! transmitted below-average accelerations.

As an additional observation, folding wheelchairs had a lower overall ACC $\left(-56.46 \mathrm{~m} / \mathrm{s}^{2}\right)$ then the much lighter rigid $\left(-57.81 \mathrm{~m} / \mathrm{s}^{2}\right)$ or rigid Ti $\left(-60.46 \mathrm{~m} / \mathrm{s}^{2}\right)$ wheelchairs on $15 \mathrm{~cm}$ curb descents. This result supports an additional hypothesis that because of their collapsible frame, folding wheelchairs are capable of vibration reduction. Even on $10 \mathrm{~cm}$ curb descents, the Quickie 2 had lower ACC than five other wheelchairs (two rigid, two rigid Ti, one suspension). This capability did not translate into a reduction in FWACC. 
Finally, the differences in wheelchair weight and distribution of weight across the frames were considered. The changes in significance that occurred when weight was added as a covariate were somewhat intuitive. A heavier wheelchair should accumulate more kinetic energy during a curb descent and therefore produce a larger impact. This larger acceleration was apparent in the loss of significant differences between suspension $(8.23 \mathrm{~kg})$ and folding $(9.08 \mathrm{~kg})$ wheelchairs. Another interesting change in significance occurred between the suspension wheelchairs and the lighter rigid $(7.28 \mathrm{~kg})$ wheelchairs. The inclusion of weight caused the differences in ACC to become significant. This result suggests that during low-height curb descents, the ability of the suspension systems to absorb energy compensated for the additional weight they imposed on the wheelchairs. In addition to weighing more than either the rigid or rigid $\mathrm{Ti}$ wheelchairs, the suspension wheelchairs had the largest impact angle of any wheelchair type (Table 3). We suspect that the addition of a suspension system shifted the COM of the wheelchair forward. This shift resulted in higher impact angles, which may have compromised the suspension and introduced more vibrations. A thorough testing-based approach may be used to determine the ideal weight and position for a given suspension such that it optimizes vibration reduction.

\section{CONCLUSIONS}

This study found that suspension manual wheelchairs provide some level of vibration suppression, although the extent of their capabilities is limited by the orientation of the wheelchair during the given activity. Curb descent testing suggested that the angle at which a wheelchair impacts its landing surface can notably influence the effectiveness of its suspension. As curb height increased, so too did the frame angle required to maintain a stable wheelie throughout the descent, which resulted in a larger suspension angle and reduced the likelihood that the suspension element would properly compress and dissipate the energy associated with impact. In addition, the type of suspension element(s) used by the system may limit the ability of the wheelchair to reduce vibrations generated under high-load conditions. Of all suspension wheelchairs tested, the Quickie XTR featured the most advanced and properly oriented suspension element; consequently, it demonstrated the best vibration-suppression performance.
Elastomer-based suspension systems provided good lowlevel vibration control; however, they became relatively ineffective at reducing higher magnitude shock vibrations. Further development of suspension wheelchairs is needed to reduce current limitations and optimize their ability to protect riders from the risks associated with WBV exposure. Also, future research on suspension manual wheelchairs should focus on the energy absorption of the suspension element(s) during propulsion. Consumers and clinicians should be aware of the functional capabilities of suspension manual wheelchairs to help ensure proper wheelchair selection. The results of this study are limited to a specific, controlled task; however, the implications of these findings may be applied to other activities or obstacles and should still be considered when evaluating the appropriateness of a suspension manual wheelchair for a particular user.

\section{ACKNOWLEDGMENTS}

We would like to thank Eugene Komaroff, PhD, and Peter Hunt, $\mathrm{PhD}$, for their help performing the statistical analyses for the study; Erik J. Wolf, PhD, and the students and staff of the Human Engineering Research Laboratories for their selfless efforts that made data collection and analysis possible; and the test pilot for his dedication and patience during the long and demanding data collection process.

This material was based on work supported by the National Institute on Disability and Rehabilitation Research, the Rehabilitation Engineering Research Center (grant H133E990001), and the VA Rehabilitation Research and Development Service (grant F2181C).

The authors have declared that no competing interests exist.

\section{REFERENCES}

1. Griffin MJ. Handbook of human vibration. San Diego (CA): Academic Press; 1990.

2. Wilder DG, Pope MH. Epidemiological and aetiological aspects of low back pain in vibration environments-An update. Clin Biomech (Bristol, Avon). 1996;11(2):61-73. [PMID: 11415601]

3. Pope MH, Wilder DG, Magnusson ML. A review of studies on seated whole body vibration and low back pain. Proc Inst Mech Eng [H]. 1999;213(6):435-46. [PMID: 10635692] 
4. Bovenzi M, Hulshof CT. An updated review of epidemiologic studies on the relationship between exposure to whole-body vibration and low back pain (1986-1997). Int Arch Occup Environ Health. 1999;72(6):351-65. [PMID: 10473835$]$

5. Lings S, Leboeuf-Yde C. Whole-body vibration and low back pain: A systematic, critical review of the epidemiological literature 1992-1999. Int Arch Occup Environ Health. 2000;73(5):290-97. [PMID: 10963411]

6. El-Khatib A, Guillon F. Lumbar intradiscal pressure and whole-body vibration-First results. Clin Biomech (Bristol, Avon). 2001;16 Suppl 1:S127-34. [PMID: 11275350$]$

7. Matsumoto Y, Griffin MJ. Effect of phase on human response to vertical whole-body vibration and shockAnalytical investigation. J Sound Vibration. 2002;250(5): 813-34.

8. Pope MH, Goh KL, Magnusson ML. Spine ergonomics. Ann Rev Biomed Eng. 2002;4:49-68. [PMID: 12117750]

9. Blüthner R, Seidel H, Hinz B. Myoelectric response of back muscles to vertical random whole-body vibration with different magnitudes at different postures. J Sound Vibration. 2002;253(1):37-56.

10. Matsumoto Y, Griffin MJ. Effect of muscle tension on nonlinearities in the apparent masses of seated subjects exposed to vertical whole-body vibration. J Sound Vibration. 2002;253(1):77-92.

11. Hinz B, Seidel H, Menzel G, Blüthner R. Effects related to random whole-body vibration and posture on a suspended seat with and without backrest. J Sound Vibration. 2002; 253(1):265-82.

12. Seidel H, Griffin MJ. Modeling the response of the spinal system to whole-body vibration and repeated shock. Clin Biomech (Bristol, Avon). 2001;16 Suppl 1:S3-7. [PMID: 11275337]

13. Matsumoto Y, Griffin MJ. Modeling the dynamic mechanisms associated with the principal resonance of the seated human body. Clin Biomech (Bristol, Avon). 2001;16 Suppl 1: S31-44. [PMID: 11275341]

14. Matsumoto Y, Griffin MJ. Non-linear characteristics in the dynamic responses of seated subjects exposed to vertical whole-body vibration. J Biomech Eng. 2002;124(5):527-32. [PMID: 12405595]

15. Nawayseh N, Griffin MJ. Non-linear dual-axis biodynamic response to vertical whole-body vibration. J Sound Vibration. 2003;268(3):503-23.

16. Samuelsson K, Larsson H, Thyberg M, Tropp H. Back pain and spinal deformity-Common among wheelchair users with spinal cord injuries. Scand J Occup Ther. 1996;3:28-32.

17. Hoover AE, Cooper RA, Dan D, Dvorsnak M, Cooper R, Fitzgerald SG, Boninger ML. Comparing driving habits of wheelchair users: Manual versus power. In: Proceedings of the Rehabilitation Engineering and Assistive Technology
Society of North America (RESNA) 26th International Conference on Technology \& Disability: Research, Design, Practice, and Policy; 2003 Jun 19-23; Atlanta, GA. Arlington (VA): RESNA Press; 2003.

18. VanSickle DP, Cooper RA, Boninger ML. Road loads acting on manual wheelchairs. IEEE Trans Rehabil Eng. 2000; 8(3):371-84. [PMID: 11001517]

19. Kwarciak AM, Cooper RA, Wolf EJ. Effectiveness of rear suspension in reducing shock exposure to manual wheelchair users during curb descents. In: Proceedings of the Rehabilitation Engineering and Assistive Technology Society of North America (RESNA) 25th Annual Conference; 2002 Jun 27-Jul 1; Minneapolis, MN. Arlington (VA): RESNA Press; 2002. p. 365-67.

20. Hostens I, Papaioannou Y, Spaepen A, Ramon H. A study of vibration characteristics on a luxury wheelchair and a new prototype wheelchair. J Sound Vibration. 2003;266(3): 443-52.

21. Tai C, Liu D, Cooper RA, DiGiovine MM, Boninger ML. Analysis of vibrations during manual wheelchair use. Saudi J Disabil Rehabil. 1998;4(3):186-91.

22. Kwarciak AM, Cooper RA, Ammer WA, Fitzgerald SG, Boninger ML, Cooper R. Fatigue testing of selected suspension manual wheelchairs using ANSI/RESNA standards. Arch Phys Med Rehabil. 2005;86(1):123-29. [PMID: 15641002]

23. Cooper RA, Wolf EJ, Fitzgerald SG, Boninger ML, Ulerich R, Ammer WA. Seat and footrest shocks and vibrations in manual wheelchairs with and without suspension. Arch Phys Med Rehabil. 2003;84(1):96-102. [PMID: 12589628]

24. DiGiovine CP, Cooper RA, Fitzgerald SG, Boninger ML, Wolf EJ, Guo S. Whole-body vibration during manual wheelchair propulsion with selected seat cushions and back supports. IEEE Trans Neural Syst Rehabil Eng. 2003; 11(3):311-22. [PMID: 14518796]

25. VanSickle DP, Cooper RA, Boninger ML, DiGiovine CP. Analysis of vibrations induced during wheelchair propulsion. J Rehabil Res Dev. 2001;38(4):409-21. [PMID: 11563494]

26. Wolf EJ, Cooper RA, Kwarciak AM. Analysis of wholebody vibrations of suspension manual wheelchairs: Utilization of the absorbed power method. In: Proceedings of the Rehabilitation Engineering and Assistive Technology Society of North America (RESNA) 25th Annual Conference; 2002 Jun 27-Jul 1; Minneapolis, MN. Arlington (VA): RESNA Press; 2002. p. 303-5.

27. Corfman TA, Cooper RA, Fitzgerald SG, Cooper R. Tips and falls during electric powered wheelchair driving: Effects of seatbelt use, legrests, and driving speed. Arch Phys Med Rehabil. 2003;84(12):1797-1802. [PMID: 14669186$]$

28. International Standards Organization (ISO). ISO 2631-1: 1997, Mechanical vibration and shock-Evaluation of 
human exposure to whole-body vibration-Part 1: General requirements. Geneva (Switzerland): ISO; 1997.

29. Fitzgerald SG, Yoest LM, Cooper RA, Downs F. Comparison of laboratory and actual fatigue life for three types of manual wheelchairs. In: Proceedings of the Rehabilitation Engineering and Assistive Technology Society of North America
(RESNA) 2001 Annual Conference; 2001 Jun 22-25; Reno, NV. Arlington (VA): RESNA Press; 2001. p. 352-54.

Submitted for publication November 1, 2006. Accepted in revised form June 27, 2007. 